\title{
スフェロマク緩和現象の三次元シミュレ一ション
}

片山弘造, 山田知穂, 桂井 誠

( 東京大学工学部電子工学科)

( 1984 年 4 月 13 日 受 理)

\section{Three dimensional simulation of relaxation process in spheromak configuration}

\author{
Kozo Katayama, Tomoho Yamada and Makoto Katsurai
}

(Received April 13, 1984)

\begin{abstract}
Relaxation processes toward the lower energy states in spheromak configurations were studied by means of three dimensional magnetohydrodynamic simulations. For the initial conditions, two cases of equilibrium states were given and the temporal evolutions of the instabilities were investigated in the nonlinear regime.

In the first case, which has a high $q$-profile ( 1.7 at the magnetic axis), the poloidal flux amplification was observed through the development of a $m=1, n=1$ mode. This process can be explained by the Kadomtsev internal disruption model.

In the second case, which has a low $q$-profile ( 0.12 at the magnetic axis), magnetic flux conversion from the poloidal to the toloidal direction toward the Taylor minimum energy state was observed through the development of a $m=1, n=4$ kink mode. It is expected that this process is related to the self-reversal mechanism in a reversed field pinch.

スフェロマク配位は逆転磁場ピンチ同様, 基本的には J. B. Taylor のエネルギー緩和理論 ${ }^{1)}$ 亿従 って形成され，あるいは維持されるものと理解されている。実験的には，同軸プラズマガンによる形 成時にポロイダル磁束の増倍が観測されている他 ${ }^{2)}$, 3)，磁気へリシティの外部からの連続的注入に よりスフェロマクの定常化を図る試みもなされている4)。また, トカマクと同じような緩和振動, デ
\end{abstract}

Department of Electronic Engineering, University of Tokyo 


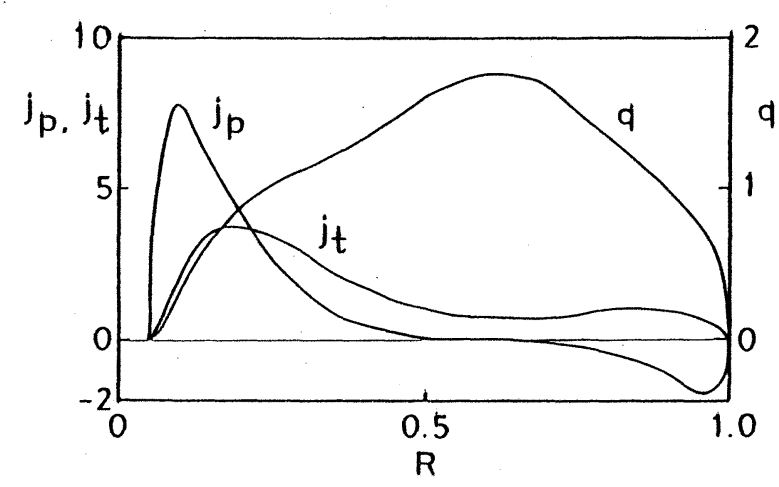

Fig. I Initial current distribution and q-profile (case A)

イスラプションといった現象も報告されている5)。そと で, 何らかの原因で不安定な状態となったスフェロマク が, 如何なる機構で新たな状態へ緩和していくのか調査 するととを目的として三次元MHDシえュレーションを 行った。

今回報告するのは初期条件としてかなり大きな q 值を 有する配位を選んだ場合(A)と，逆に，小さな q 值を有 する場合(B) 2 例である。

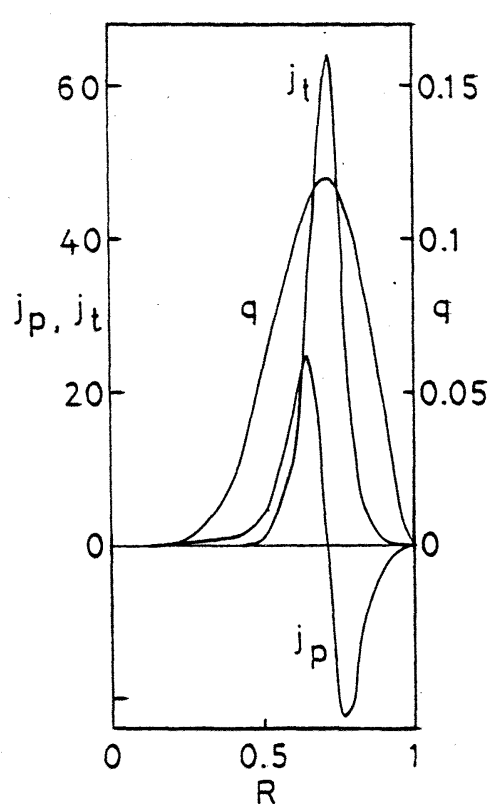

Fig. 2 Initial current distribution and $\mathrm{q}$-profile (case $\mathrm{B}$ )

シミュレーションは半径 $\mathrm{R}=1$, 高さ $\mathrm{L}=1$ の円筒完全導体容器を想定し, 導体壁はスフェロマ クのセパラトリクスに接している。初期条件は Grad-Shafranov 方程式を数值的に解くととにより 与える。第 1 図に(A)の場合, 第 2 図に(B)場合のトロイダル電流密度 $\mathrm{j} t$, ポロイダル電流密度 $\mathrm{j} p$, $\mathrm{q}$ 值の半径方向の分布を示す。(A)ではプラズマの表面近くに電流のピークが生じ, 磁気軸上での q 值 $\mathrm{q}_{\mathrm{a}}$ は 1.7 である。それに対し(B)では, 磁気軸上に鋭いピークを有する電流分布で $\mathrm{q}_{\mathrm{a}}=0.12$ とな っている。

シミュレーションコードは 2 ステップ Lax-Wendroff 法を用いた三次元非線形MHDコードであ り, (A)では円筒座標, B ではデカルト座標を用いている。(A)の場合には発生する不安定性のトロイダ ルモード数 $\mathrm{n}$ が小さいため, トロイダル方向の分割をポロイダル面内に較べ粗くとるととができる円 筒座標が有利である。ととでは， $\mathrm{r}$ 方向， $\varphi$ 方向， $z$ 方向の格子点数を $29 \times 16 \times 30$ に選んだ。一 方(B)では， $\mathrm{n}$ の比較的大きなモードの発生が予測され, 均質な分割の得られるデカルト座標を採用 

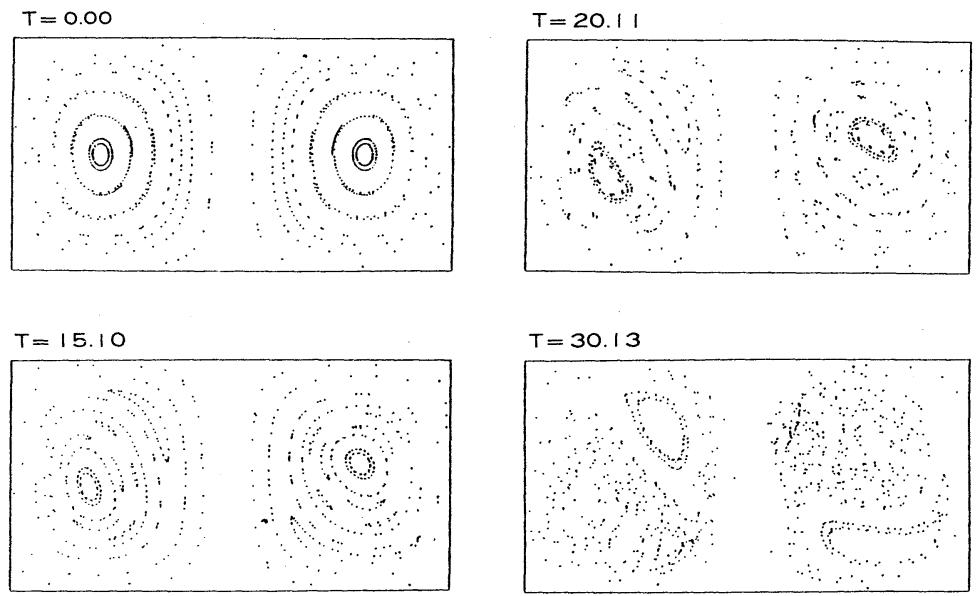

Fig. 3 Magnetic surfaces (case A)

した。格子点数は $53 \times 53 \times 26$ である。乙の場合, 計算は円筒境界の内側でのみ行われ, 境界に近

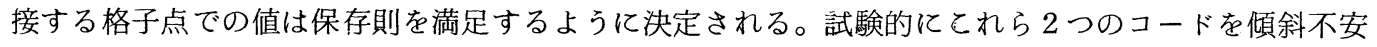
定のシミュレーションに適用したととろ, ほぼ同等の結果を得ている。

またレイノルズ数及び磁気レイノルズ数は $5 \times 10^{3}$ 亿設定した。ことで特性長は円筒半径 R, 特徵 的速度として $\mathrm{v}_{\mathrm{A}}=\mathrm{B}_{\mathrm{o}} / \sqrt{\mu_{\mathrm{o}} \rho}\left(\mathrm{B}_{\mathrm{o}}\right.$ : 磁気軸での磁気の強さ)を用いている。なお, 今回のシ レーションでは, 簡単化のため圧力 $\mathrm{p}=0$, 密度 $\rho=$ 一定の仮定を設けた。

第 3 図は(A)の場合について不安定性の成長に伴う磁気面の変形を示したものである。 $q=1$ の有 理面上に $\mathrm{m}=1$ の磁気島が発生し, 内側には $\mathrm{m}=3, \mathrm{~m}=4$ の磁気島も見られる。時間の経過と共 に $\mathrm{m}=1$ の磁気島が成長し, 本来の磁気軸周辺の磁気面は破壊され,エルゴード的になっているてと がわかる。 $\mathrm{t}=30 \tau_{\mathrm{A}}\left(\tau_{\mathrm{A}}=\mathrm{R} / \mathrm{v}_{\mathrm{A}}\right)$ では $\mathrm{m}=1$ の磁気島が半分程度の領域を占めるが $\mathrm{t}=40$ $\tau_{\mathrm{A}}$ を過ざると磁気面は全領域で破壊されてしまう。

第 4 図はスフェロマクの保持するポロイダル磁束 $\psi$, トロイダル磁束 $\phi$, および $\mathrm{Wm} / \mathrm{K}\left(\right.$ こてで $\left.\mathrm{Wm}=\int_{\mathrm{v}} \frac{1}{2} \mathrm{~B}^{2} \mathrm{~d} \mathrm{v}, \mathrm{K}=\int_{\mathrm{v}} \mathbf{A} \cdot \mathbf{B} \mathrm{dv}\right)$ の時間変化を示したものである。図中には，Taylor のエネルギー最小状態に完全に緩和したときに得ら れるポロイダル磁束, トロイダル磁束, Wm/K, ならびに, Kadomtsev - Reimann の m=1 モード による内部ディスラプションモデル6)，7） を仮定した場合に形成されるポロイダル磁束の大きさをあわせ

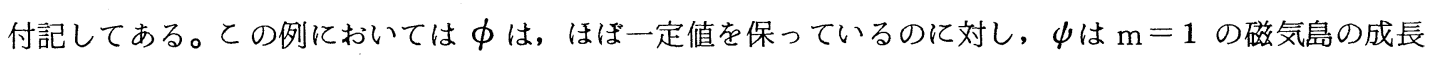
が顕著となる $\mathrm{t}=20 \tau_{\mathrm{A}}$ 以降増大し, $\mathrm{t}=40 \tau_{\mathrm{A}}$ では Kadomtsev モデルの値に近でいている。しかし, 
完全な定常状態には達していない。この過 程において, 磁気ヘリシティ $\mathrm{K} は$ 保存され ているが，不安定性により解放されるWm が小さいためWm / Kの值はほぼ横ばいで ある。

(B)の場合, 初期状態のWm / K がTaylor 状態のWm/Kに比較して極めて大きく, より明確な緩和現象が見られる。第 5 図は 円筒の中心対称軸に垂值な平面上での磁場 ベクトルを各時刻について表示したもので ある。 $\mathrm{m}=1, \mathrm{n}=4$ のキンクモードの激 しい成長により, 軸対称であった磁場は $\mathrm{t}=10 \tau_{\mathrm{A}}$ においては初期状態の磁気軸の

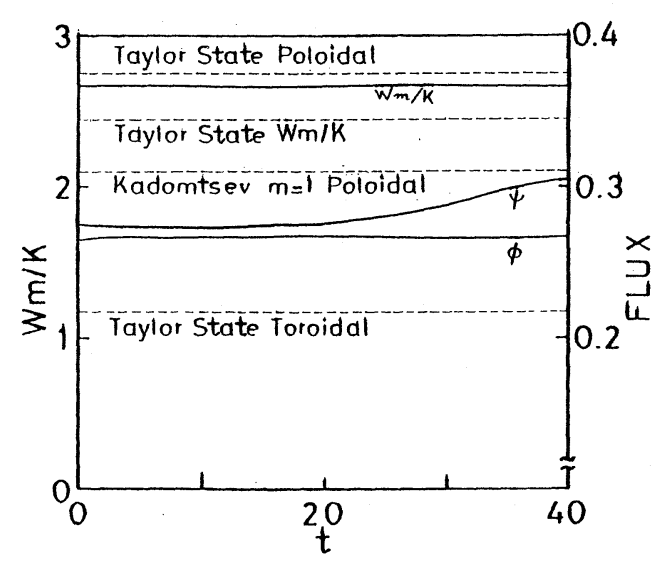

Fig. 4 Temporal evolution of poloidal flux, toroidal flux and $\mathrm{Wm} / \mathrm{K}$ (case A)
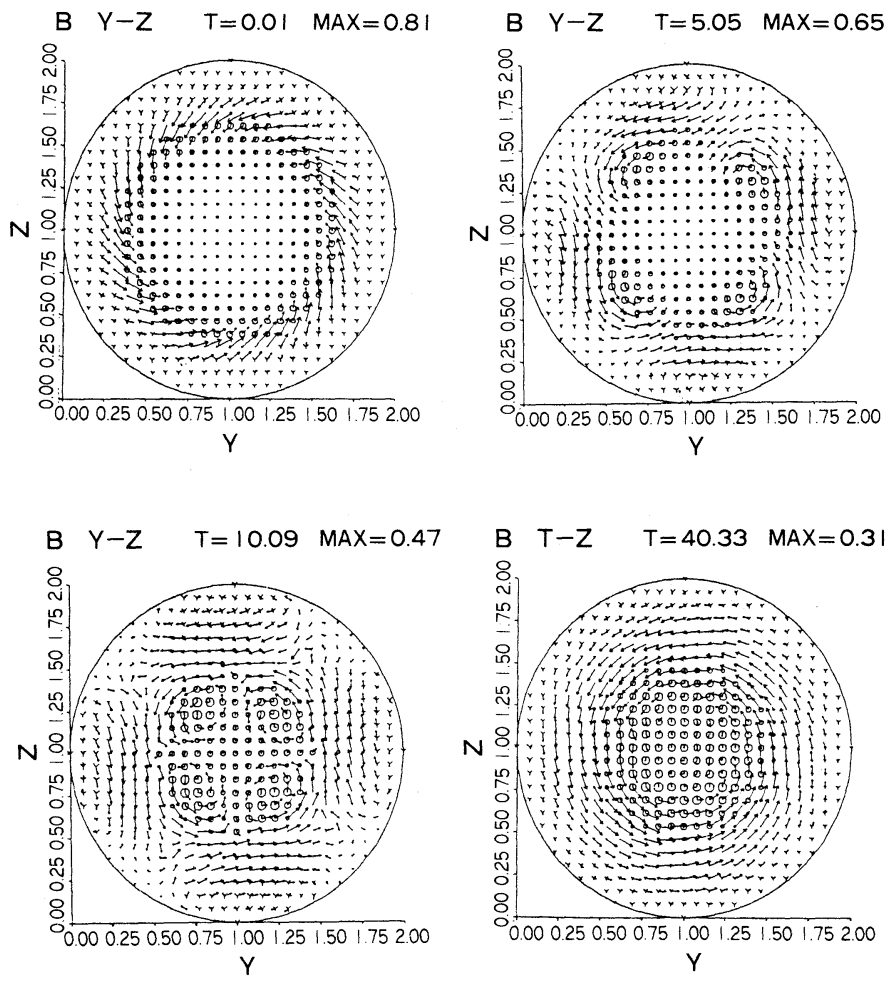

Fig. 5 Magnetic field on the plane normal to the axis of cylinder (case B) 
研究開発ノート

位置の内側と外側に 4 個ずつ計 8 個の渦構造に分裂している。その結果, 円筒境界近くとトーラスの 内側に反転磁界が生じているのがわかる。ての過程は $\mathrm{m}=1$ のキンクによる逆転磁場の自己形成モ デル $\left.{ }^{8)}, 9\right)$ と類似のものである。しかし, 今の場合, 領域が単連結であるため 4 個の渦構造は中心軸上 で合体し, 軸対称状態が最終的に再現される。

第 6 図は $\psi, \phi, \mathrm{Wm} / \mathrm{K}$ の時間変位を 示したものである。 $\psi$ は不安定成長の結果 減少し, фは増大して, ほぶ Taylor 状態 に近い值を得ている。

以上のように, 三次元シぇュレーション によりスフェロマクの緩和過程を調べた結 果, トロイダル磁束がポロイダル磁束より 小さく q 值の小さい場合についてはキンク の成長により, Taylor の最小エネルギー 状態に向けて,ポロイダル磁束からトロイ ダル磁束への変換が生じるととが確認され た。逆に, トロイダル磁束が大きく， q 值 の大きい場合には, ポロイダル磁束が増倍 される。このときの増倍量はKadomtsev一 Beimann のモデルで説明可能であるが完 全な定常状態を得るには至っていない。磁

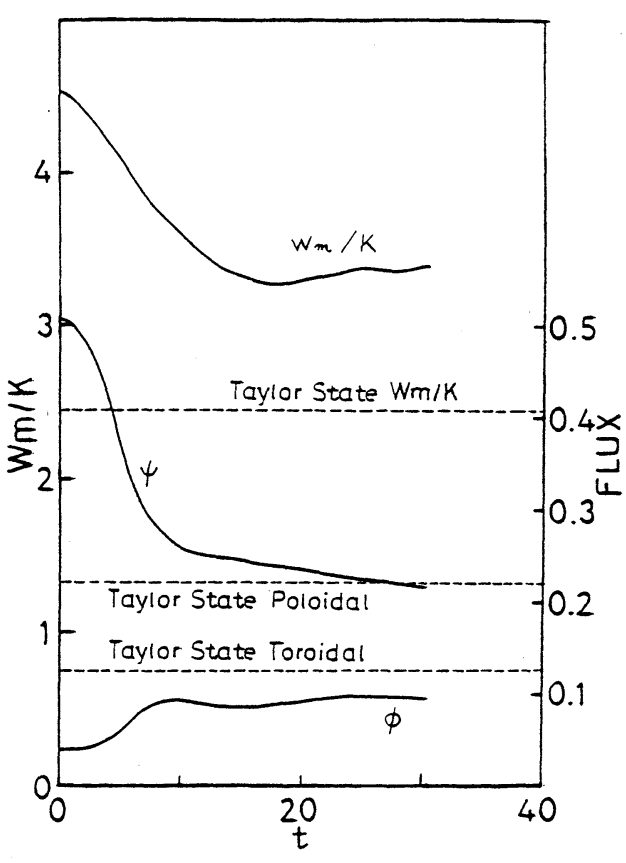

Fig. 6 Temporal evolution of poloidal flux. toroidal flux and $\mathrm{Wm} / \mathrm{K}$ (case $\mathrm{B}$ )

気面が破壊された後, さらに緩和の進むと とも予想される。

参考文献

1) J. B. Taylor, Phys. Rev. Lett. 33, 1139 (1974)

2) L. Lindberg and C. Jacobsen, Astrophys. J. 133, 1043 (1961)

3) W. C. Turner et al., Phys. Fluids 26, 1965 (1983)

4) T. R. Jarboe et al., Phys. Rev. Lett. 51, 39 (1983)

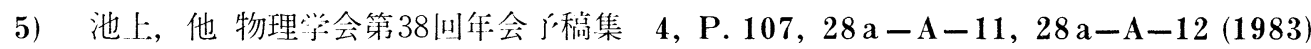

6) B. B. Kadomtsev, Sov. J. Plasma Phys. 1,389 (1975) 
7) A. Reimann, Phys. Fluids 25, 1885 (1982)

8) T. Sato, K. Kusano and T. Hayashi, Hift-71, Feb. 1983

9) A. Y. Aydemir and D. C. Barnes, Phys. Rev. Lett. 52, 930 (1984) 